\title{
Effects of 1.8 GHz Radiofrequency Fields on the Emotional Behavior and Spatial Memory of Adolescent Mice
}

\author{
Jun-Ping Zhang ${ }^{1,+}$, Ke-Ying Zhang ${ }^{1,+}$, Ling Guo ${ }^{1}$, Qi-Liang Chen ${ }^{1}$, Peng Gao ${ }^{2}$, Tian Wang ${ }^{1}$, \\ Jing $\mathrm{Li}^{1}$, Guo-Zhen Guo ${ }^{2}$ and Gui-Rong Ding ${ }^{1, *}$ \\ 1 Department of Radiation Biology, Faculty of Preventive Medicine, Fourth Military Medical University, \\ 169\# Chang Le West Road, Xi'an 710032, China; xp10260641@163.com (J.-P.Z.); \\ zhangky@fmmu.edu.cn (K.-Y.Z.); guolingclover@163.com (L.G.); chenqiliang23@163.com (Q.-L.C.); \\ scuwangtian1989@sina.cn (T.W.); jingli@fmmu.edu.cn (J.L.) \\ 2 Department of Radiation Medicine, Faculty of Preventive Medicine, Fourth Military Medical University, \\ 169\# Chang Le West Road, Xi'an 710032, China; patriciag@126.com (P.G.); guozhen@fmmu.edu.cn (G.-Z.G.) \\ * Correspondence: dingzhao@fmmu.edu.cn; Tel.: +86-29-8477-9279 \\ + These authors contributed equally to the work.
}

Received: 8 September 2017; Accepted: 2 November 2017; Published: 5 November 2017

\begin{abstract}
The increasing use of mobile phones by teenagers has raised concern about the cognitive effects of radiofrequency (RF) fields. In this study, we investigated the effects of 4-week exposure to a $1.8 \mathrm{GHz} \mathrm{RF}$ field on the emotional behavior and spatial memory of adolescent male mice. Anxiety-like behavior was evaluated by open field test (OFT) and elevated plus maze (EPM) test, while depression-like behavior was evaluated by sucrose preference test (SPT), tail suspension test (TST) and forced swim test (FST). The spatial learning and memory ability were evaluated by Morris water maze (MWM) experiments. The levels of amino acid neurotransmitters were determined by liquid chromatography-mass spectrometry (LC-MS). The histology of the brain was examined by hematoxylin-eosin (HE) staining. It was found that the depression-like behavior, spatial memory ability and histology of the brain did not change obviously after RF exposure. However, the anxiety-like behavior increased in mice, while, the levels of $\gamma$-aminobutyric acid (GABA) and aspartic acid (Asp) in cortex and hippocampus significantly decreased after RF exposure. These data suggested that RF exposure under these conditions do not affect the depression-like behavior, spatial memory and brain histology in adolescent male mice, but it may however increase the level of anxiety, and GABA and Asp were probably involved in this effect.
\end{abstract}

Keywords: RF field; anxiety-like behavior; depression-like behavior; spatial memory; amino acid neurotransmitters

\section{Introduction}

With the widespread use of mobile phones in modern life, adolescents are exposed to radiofrequency $(\mathrm{RF})$ fields from mobile phones and base stations much more frequently than ever. According to one report, $90 \%$ of adolescents have a mobile phone and about $40 \%$ of them are considered as heavy mobile phone users [1]. Therefore, this has raised public concerns about the potential health hazard of RF fields on adolescents.

$\mathrm{RF}$ field is a kind of electromagnetic radiation with frequencies ranging from $100 \mathrm{kHz}$ to $300 \mathrm{GHz}$, which is used extensively in wireless communications, such as mobile phones, radios and televisions. The RF field produced by mobile phones and base stations is mainly at the frequencies of $800-2000 \mathrm{MHz}$ [2]. It was reported that the average field density of the mobile phone antenna nearby 
was about $200 \mu \mathrm{W} / \mathrm{cm}^{2}-300 \mu \mathrm{W} / \mathrm{cm}^{2}$ [3], exceeding the limit stipulated by the national standard in China $\left(40 \mu \mathrm{W} / \mathrm{cm}^{2}\right)$ [4].

The head receives much more RF energy than any other part of body because the mobile phone is usually held at the ear during communication. Whether RF exposure results in brain dysfunction, has become a major topic of investigation [5]. Based on the evidence from epidemiological and laboratory studies, RF fields in the $30 \mathrm{kHz}-300 \mathrm{GHz}$ frequency range were classified as a possible human carcinogen (Group 2B) by the International Agency for Research on Cancer (IARC) in 2011 [6]. In addition, it was reported that exposure to RF fields could cause insomnia, headache, tinnitus, fatigue, cognitive disturbances, dysesthesias (abnormal sensation), dizziness, and depression [7-9].

In terms of the effects of RF field on brain function, Wang found that although single exposure to $1800 \mathrm{MHz}$ RF field for $30 \mathrm{~min}$ with specific absorption rates (SARs) in brain at 2.42, 2.86 and $3.3 \mathrm{~W} / \mathrm{kg}$ did not affect spontaneous locomotor activity, it increased recognition memory in mice [10]. In addition, Bouji reported that after exposing the heads of the animals to $900 \mathrm{MHz}$ RF field for 1 month (SAR $6 \mathrm{~W} / \mathrm{kg}, 45 \mathrm{~min} /$ day), the spatial memory, emotional memory and locomotor activity did not change, but the anxiety-related behavior decreased in male senescent rats [11]. Arendash reported that exposure to $918 \mathrm{MHz} R F$ field (SAR: $0.25 \mathrm{~W} / \mathrm{kg}$, $1 \mathrm{~h} /$ day for $4-7$ months) could protect against and reverse cognitive impairment in Alzheimer's disease mice [12]. However, some adverse effects were also reported. Aldad found that exposure to 800-1900 MHz-rated cellular telephones resulted in memory impairments in fetal mice [13]. In addition, Daniels reported that although exposure to $840 \mathrm{MHz}$ RF field (power density: $60 \mu \mathrm{W} / \mathrm{m}^{2}, 3 \mathrm{~h} /$ day for 13 days) had no effect on spatial memory and brain morphology, it decreased the locomotor activity in rats [14].

Over all, the effects of RF exposure on animal behaviors and memory remain inconclusive. In present study, we explored the effects of 4-week exposure to $1.8 \mathrm{GHz}$ RF field on the emotional behavior and spatial memory in adolescent male mice.

\section{Materials and Methods}

\subsection{Animals and Groups}

A total of 70 male C57BL/ 6 mice (4 weeks old), purchased from the Experimental Animal Center of Fourth Military Medical University, were randomly divided into RF exposure group and sham exposure group. The animals were whole body exposed or sham exposed to RF field for 4 weeks, $6 \mathrm{~h} /$ day. After exposure, mice in both RF group and sham group were divided into three sub-groups, respectively, according to the detection endpoints. Animals in the first sub-group $(n=10)$ were used for open field tests (OFT), sucrose preference tests (SPT) and tail suspension tests (TST), while animals in the second sub-group $(n=10)$ were used for the elevated plus maze $(E P M)$ and forced swim test $(F S T)$, and animals in the third sub-group $(n=15)$ were used for the Morris water maze (MWM) assay. All animals were kept in a controlled environment $\left(25 \pm 2{ }^{\circ} \mathrm{C}, 12\right.$-h light and 12-h dark cycle), and they were handled daily and allowed to acclimate to the laboratory for 1 week before the start of the experiments. All experiments reported in this study were conducted according to an experimental protocol approved by the Animal Use and Care Committee for Research and Education of Fourth Military Medical University (20160105, Xi'an, China).

\subsection{Radiofrequency Field Exposure}

The 1.8 GHz RF exposure system (East China Normal University, Shanghai, China), which has been described elsewhere [10], is comprised of a RF signal source, a movable loading platform and a computer. The mice in the exposure group were placed freely in a plastic box with bedding ( $35 \times 24 \times 24 \mathrm{~cm}$ with small ventilation holes on the walls). Mice were exposed to $1.8 \mathrm{GHz}$ frequency field for 28 days, $6 \mathrm{~h} /$ day (9:00 AM to 3:00 PM). During exposure, the animals had access to food and water. The SAR of whole body and brain were approximately $2.7 \mathrm{~W} / \mathrm{kg}$ and $2.2 \mathrm{~W} / \mathrm{kg}$ at a distance of $1 \mathrm{~m}$ from the antenna. Since the incidence and polarization of free movement mice kept 
changing during exposure, the deviation between the average SAR value and the maximum and the minimum of SAR was about $8 \%$. The power density in this study was $530 \mu \mathrm{W} / \mathrm{cm}^{2}$, as measured by an electromagnetic field meter (PMM8053A, PMM Costruzioni Electtroniche Centro Misure Radio Electriche S.r.l., Milan, Italy). A dosimetry assessment similar to that of a previous report [10] was used in this study. Briefly, the average SARs of whole body and brain were calculated using XFDTD7.2.3 (Remcom Inc., State College, PA, USA) and the reference electric constants of the tissues were derived from http:/ / transition.fcc.gov/oet/rfsafety/dielectric.html. During exposure, the mice were awake and quiet and they did not show any abnormal physical responses to the RF signals. Sham group mice underwent exposure in the same way as RF group mice but the control system was turned off.

During exposure, we simultaneously measured the surface body temperature of mice with an infrared thermal camera (Fluke Ti400 Thermal Imager, Fluke Corporation, Everett, WA, USA). It was found that exposure to $2.70 \mathrm{~W} / \mathrm{kg}$ RF field did not obviously affect the surface body temperature of mice (Figure 1), which suggested that no gross thermal effects were involved. Additionally, the air temperature of the exposure cage with a temperature hygrometer was measured and the results showed that air temperature difference did not exceed $0.1^{\circ} \mathrm{C}$ during $6 \mathrm{~h}$ exposure.

a

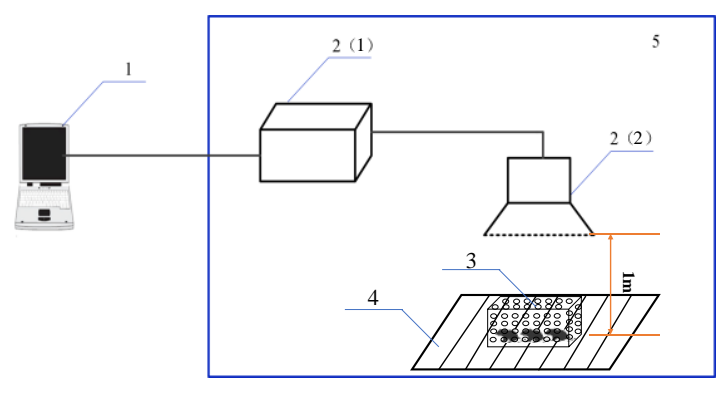

b

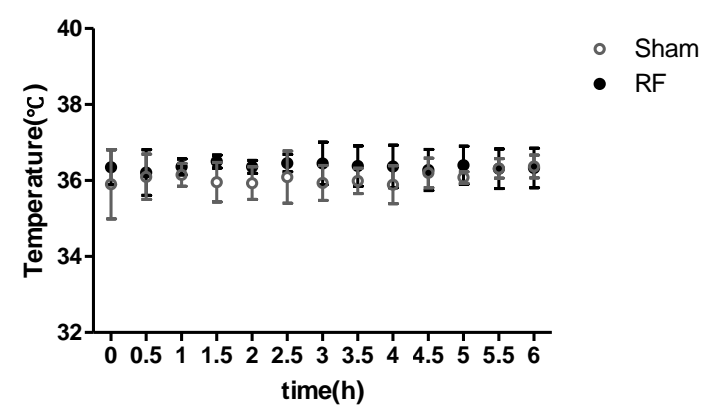

Figure 1. Schematic diagram of experimental set-up of the RF-EMR-exposure system (a) 1. Control system: a computer; 2. Microwave signal source. (1). Microwave source; (2). Horn antenna; 3. Experiment animals were placed at a plastic box $(35 \times 24 \times 24 \mathrm{~cm})$ with many vents on their walls; 4. Experiment platform; 5. Shielded room. Time course of changes in mice surface body temperature during $1.8 \mathrm{GHz}$ RF field exposure $(\mathbf{b})$. Data were represented as the mean $\pm \mathrm{SD} . \mathrm{N}=6$ for each group (within group: $\mathrm{df}=12, \mathrm{~F}=0.323, P=0.984$; between groups: $\mathrm{df}=1, \mathrm{~F}=2.721, P=0.130$ ); RF: radiofrequency.

\subsection{Behavior Assessment}

$24 \mathrm{~h}$ after 28-day RF exposure (29th day) OFT, EPM, TST and FST were assessed. SPT was conducted from 25th (exposure day) to 29th day, and MWM was carried out from 24th (exposure day) to 29th day. Mice were habituated to the testing room for more than half an hour before the behavioral test.

\subsubsection{Open Field Test (OFT)}

OFT is commonly used to assess locomotor activity, exploratory and anxiety-related behavior in rodents. The open field apparatus was consisted of a clear plexiglass box $(23 \times 23 \times 35 \mathrm{~cm})$ with a white floor. Mice were placed in the center of the apparatus to measure the total distance moved for 5 min under a dim light (20 lx) by a computer-controlled tracking system (Mobile Datum Information Technology Co., Ltd., Shanghai, China). The accumulative distance and the time spent in the central area of the apparatus were also measured to evaluate the level of anxiety. After each individual test, apparatus was cleaned with alcohol solution. 


\subsubsection{Elevated Plus Maze (EPM)}

EPM was performed to evaluate the anxiety-like behaviors based on the natural aversion of rodents for open and elevated areas. The instrument was consisted of two closed arms and two open arms, which were made of acryl material and placed at the height of $50 \mathrm{~cm}$ above the floor. At the beginning of each test, the mouse was placed in the central area facing open arms and was allowed to explore freely for $5 \mathrm{~min}$. The animals' movements track was recorded with a digital camera and analyzed by software (Mobile Datum Information Technology Co., Ltd., Shanghai, China). Total entries into the arms, percentage of time spent in open arms, and percentage of entries in open arms were analyzed. The maze was cleaned before each test with alcohol solution.

\subsubsection{Sucrose Preference Test (SPT)}

SPT was generally acknowledged as one of the most effective ways to detect the depression-like behavior according to the natural sugar water preference of rodents. The test lasted for five days and every mouse was fed in single cage during the test. Each mouse was given two bottles of water in the first day afternoon. In the second day afternoon within the compartment, the water in one of two bottles was changed to $2.5 \%$ sugar water and kept there for next two days. In the fourth day afternoon, $2.5 \%$ sugar water was replaced by $1 \%$ sugar water, and then, the intake of the $1 \%$ sugar water and normal water were measured in the fifth day afternoon (for $24 \mathrm{~h}$ ). In order to avoid the preference of position, two bottles' positions were exchanged in the intermediate time. The water preference index was calculated according to $100 \% \times$ (the sugar water intake)/(the normal water intake + the sugar water intake), which was used to evaluate the depression-like behavior of each animal.

\subsubsection{Tail Suspension Test (TST)}

TST is widely used to measure depression-like behavior in rodents. The apparatus is composed of five coordinate compartments with three-walled rectangular $(55 \mathrm{~cm}$ height $\times 15 \mathrm{~cm}$ width $\times 11.5 \mathrm{~cm}$ depth). Mice were suspended with the tail within the compartment of small plastic cylinders and the approximate distance between the mouse's nose and the apparatus floor was $20-25 \mathrm{~cm}$. The total duration of immobility was measured in seconds. Notably, small movements confined to the front legs instead of the hind legs were counted as immobility. Additionally, oscillations and pendulum like swings that were due to the momentum gained during the earlier mobility bouts also counted as immobility. Every mouse was tested for $6 \mathrm{~min}$ and the duration of immobility was measured [15]. All data were analyzed by two observers who were blind to the group assignment of animals.

\subsubsection{Forced Swim Test (FST)}

FST was performed with a glass cylinder $(20 \mathrm{~cm}$ diameters $\times 30 \mathrm{~cm}$ height) filled with warm water $\left(23-25^{\circ} \mathrm{C}\right)$. The water level was $15 \mathrm{~cm}$ from the bottom so that the mice were not able to touch the bottom of the tank, either with their feet or tails, during the swimming test. A total of 6 min of testing was carried out and only the last $4 \mathrm{~min}$ of the test were analyzed. The mobility time was measured in seconds only when the mice do any movements other than those necessary to balance the body and keep the head above the water. After each test, the water in glass cylinder was changed with the fresh water at the same temperature. Mice were dried by a heat lamp (the temperature of the lamp did not exceed $32{ }^{\circ} \mathrm{C}$ ) after the test [16]. All data were analyzed by two observers who were blind to the group assignment of animals.

\subsubsection{Morris Water Maze (MWM)}

MWM was used to measure the ability of spatial learning and memory. The procedure was reported in detail by Voorhees and Williams in 2006 [17]. In brief, the water maze was a circular tank (180 cm in diameter and $60 \mathrm{~cm}$ in height) located in a room containing a variety of cues. The pool was filled with opaque water that was made by adding white food additives and the temperature 
was maintained at $22-25^{\circ} \mathrm{C}$. The tank was divided into four quadrants and an invisible platform was $1 \mathrm{~cm}$ below the surface of the water. There were four trials per day for each mouse during the 5 days training. For each trial, the mouse was randomly put into the water in one of the quadrants with its head facing the tank wall. Each mouse was allowed to swim freely until it came across and climbed on the platform and stayed there for $10 \mathrm{~s}$. In case a mouse did not reach the platform after $60 \mathrm{~s}$ swimming, it was gently hand-guided to the platform. $24 \mathrm{~h}$ after 5 th training test, the probe test was performed. Before probe test, the platform was removed, and then the mouse was allowed to swim for $60 \mathrm{~s}$. All trials were processed on line by a video track tracking system (Mobile Datum Information Technology Co., Ltd., Shanghai, China). The escape latency, the time spent in the target quadrant and the times crossing the platform were used to evaluate the mice's spatial learning and memory ability.

\subsection{Body and Organ Weight Measurements}

In this study, all animals' body weight was measured. No animals got sick or died during the experiments. The body weight was measured about every 4 days during the experiment (from 0 th to 30th day, $48 \mathrm{~h}$ after 28-day RF exposure). At the end of the behavioral experiments (30th day), 50 mice were deeply anaesthetized by sodium pentobarbital $(60 \mathrm{mg} / \mathrm{kg})$ and then the brains were isolated and weighed immediately. Subsequently, the cortex and hippocampus were removed separately, washed with cold phosphate buffered saline (PBS, pH 7.4), dried with filter paper, weighted and stored at $-80^{\circ} \mathrm{C}$ for neurotransmitters and acetylcholinesterase (AchE) detection later. Growth curve, weight gain, the ratio of the hippocampus weight to the brain weight, the ratio of the hippocampus weight to the body weight and the ratio of the brain weight to the body weight were calculated.

\subsection{Hematoxylin and Eosin (HE) Staining}

On the 30th day, 20 mice were anaesthetized as previously described and fixed via cardiac perfusion with $4 \%$ paraformaldehyde after flushing out the red blood cells with PBS. The whole brains were isolated and fixed in $4 \%$ paraformaldehyde for 1 day. The brains were then dehydrated in ethanol, defatted in xylene, embedded in paraffin, and serially sectioned at $5 \mu \mathrm{m}$ thicknesses by using a rotary microtome (Leica RM2135, Leica Biosystems, Heidelberg, Germany). Subsequently, the sections were stained with HE according to procedure which has been reported [18]. The digital photograph of hippocampal CA1, CA3 and amygdala were observed by Leica DMI4000B (Leica Biosystems, Heidelberg, Germany) and a Hamamatsu Nano Zoomer scan SQ1.0 (Hamamatsu Photonics, Shizuoka, Japan) with NDP, respectively.

\subsection{Amino Acid Neurotransmitters Detected by LC-MS}

The samples (10 hippocampi and 10 cortices from each group) were homogenized with $0.5 \mathrm{~mL}$ of $1 \%$ formic acid solution prepared in cold acetonitrile $\left(-20^{\circ} \mathrm{C}\right)$ using a homogenizer device (Leica Biosystems, Heidelberg, Germany), then the supernatant were extracted after centrifugation at $12,000 \mathrm{rpm}$ for $20 \mathrm{~min}$ at $4{ }^{\circ} \mathrm{C}$. After that, the level of amino acid neurotransmitters such as Asp, GABA, glutamic acid (Glu) and glycine (GLY) were detected by liquid chromatography-mass spectrometry (LC-MS) (AB SCIEX QTRAP®4500, SCIEX, Framingham, MA, USA) as reported [19]. This equipment was provided by the Centers for Disease Control and Prevention (CDC) of Xi'an.

\subsection{Acetylcholinesterase (AchE) Activity Detection}

The tissue (seven hippocampi and seven cortices from each group) were used to detect the activity of AchE by a commercial kit (Acetylcholinesterase Assay Kit, DACE-100, BioAssay Systems, Hayward, CA, USA). The samples were homogenized with $1.5 \mathrm{~mL}$ cold PBS ( $\mathrm{pH}$ 7.4) by a homogenate device and the supernatant were collected after centrifugation at $3000 \mathrm{rpm}$ for $20 \mathrm{~min}$ at $4{ }^{\circ} \mathrm{C}$. After that, the supernatant were used to detect the activity of AchE according to the manufacturer's protocol. 


\subsection{Statistical Analysis}

All results were presented as mean \pm standard deviation (SD). Data analysis was performed using SPSS 17.0 software (SPSS Inc., Chicago, IL, USA) by the individual blinded to group of exposure. Repeated measures analysis of variance (ANOVA) was conducted on data which was recorded in blocks across time, and student $t$-test was used on the other data. It was considered statistically significant only when $P$ value less than 0.05 .

\section{Results}

\subsection{Effects of RF Exposure on Anxiety-Like Behaviors}

The anxiety-like behaviors of mice were evaluated by OFT and EPM after RF exposure. OFT results showed that there were no significant differences in accumulative total distance traveled between the sham group and RF group (Figure 2a). However, the accumulative distance in the center area and the time spent in the central area decreased significantly in the RF group, compared with the sham group (Figure 2b,c), which indicated that 4-week RF exposure could increase the animals' anxiety-like behavior.
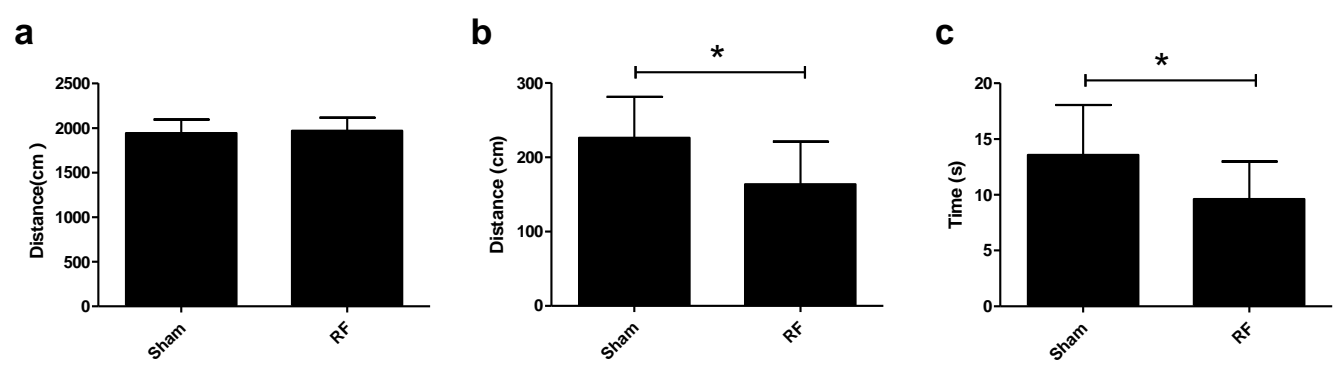

Figure 2. Effects of RF field exposure on anxiety-like behaviors. (a) Total distance traveled in OFT $(\mathrm{t}=0.385, \mathrm{df}=18, P=0.705),(\mathbf{b})$ accumulative distance in the center area in OFT $(\mathrm{t}=2.5, \mathrm{df}=18$, $P=0.022)$, (c) time spent in the central area in OFT $(\mathrm{t}=2.548, \mathrm{df}=18, P=0.020)$. All data are presented as mean $\pm \mathrm{SD}, * P<0.05$, compared with the sham group.

a

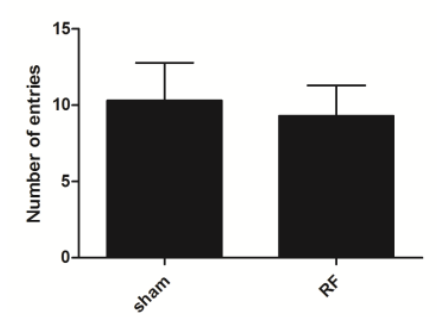

b

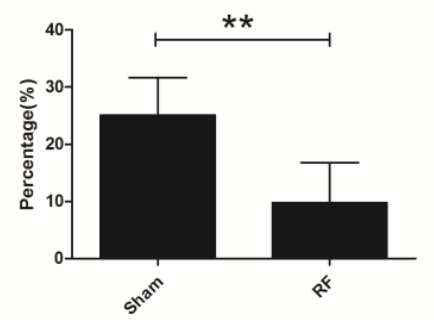

C

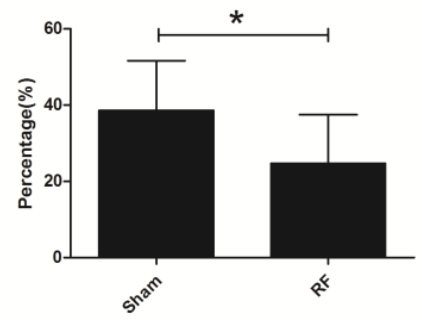

Figure 3. Effects of RF field exposure on anxiety-like behaviors. (a) Number of entries into the arms (open arms and closed arms) in EPM $(\mathrm{t}=0.988, \mathrm{df}=18, P=0.336),(\mathbf{b})$ percentage of the total time spent in the open arms in EPM $(t=5.030, \mathrm{df}=18, P<0.0001),(c)$ percentage of the entries into the open arms in $\operatorname{EPM}(t=2.411, \mathrm{df}=18, P=0.027)$. All data are presented as mean $\pm \mathrm{SD},{ }^{*} P<0.05$, ${ }^{* *} P<0.01$, compared with the sham group.

In addition, EPM results showed that there were no significant differences in the number of total entries into the arms between the sham group and RF group, which indicated that the locomotor activity in the mice did not change after RF exposure (Figure 3a). However, the percentage of the total time spent in the open arms and the percentage of the entries into the open arms decreased significantly in the RF group, compared with the sham group (Figure $3 b, c)$. These results were consistent with that of OFT. 


\subsection{Effects of RF Exposure on Depression-Like Behaviors}

In this study, SPT, TST and FST were performed to evaluate the depression-like behaviors after exposing the mice to RF field for 4 weeks. SPT results showed that there were no significant differences in the sucrose preference indices between the sham group and RF group (Figure 4a). Similarly, TST and FST results showed that there were no significant differences in the immobility time between the sham group and the RF group (Figure $4 b, c)$. These results indicated that 4 -week RF exposure could not increase depression-like behaviors in mice.

a

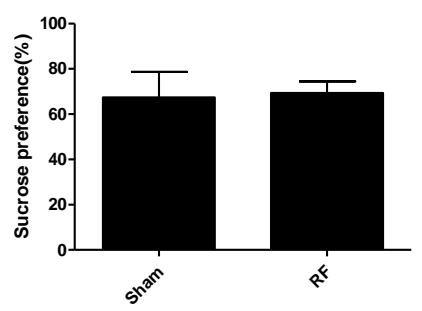

b

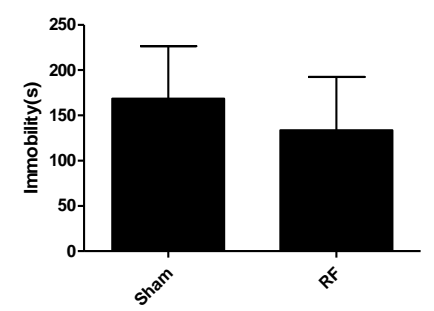

C

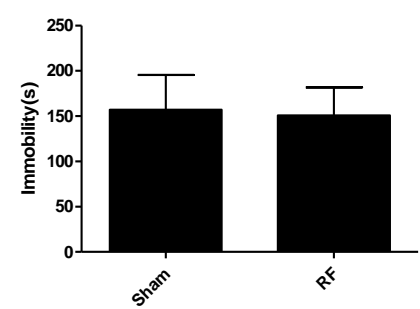

Figure 4. Effects of RF field exposure on depression-like behaviors. (a) the index of the SPT $(t=0.501$, $\mathrm{df}=18, P=0.622),(\mathbf{b})$ the immobility time of the TST $(\mathrm{t}=1.438, \mathrm{df}=18, P=0.168),(\mathrm{c})$ the immobility time of the FST $(\mathrm{t}=0.417, \mathrm{df}=18, P=0.682)$. All data are presented as mean $\pm \mathrm{SD}$. No significant difference was observed between the sham and RF groups $(P>0.05)$.

\subsection{Effects of RF Exposure on the Spatial Learning and Memory}

It was found that the escape latency in both the sham and RF groups decreased gradually as the training time was extended. However, there were no significant differences in the escape latency during the training phase between the sham group and RF group (Figure 5a). Similarly, there were no significant differences in the number of times crossing the platform and the time spent in the target quadrant between the sham group and RF group during the probe phase (Figure $5 b, c)$. These data indicated that RF exposure had no effects on the spatial learning and memory ability in mice.

a

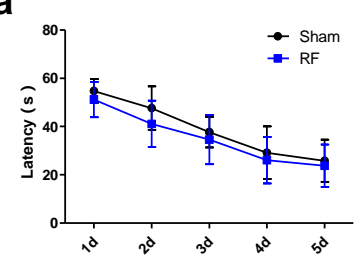

b

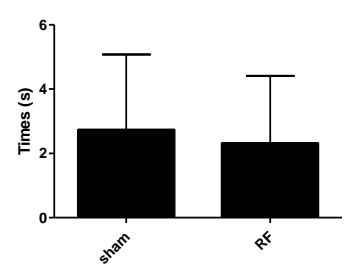

C

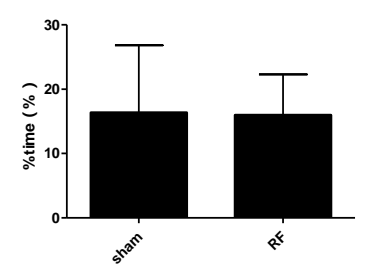

Figure 5. Effects of RF field exposure on the spatial learning and memory. (a) the escape latency in training phase (within group: $\mathrm{df}=4, \mathrm{~F}=68.17, P<0.001$; between groups: $\mathrm{df}=1, \mathrm{~F}=3.185, P=0.085$ ), (b) the number of times crossing the platform area in probe phase $(\mathrm{t}=0.290, \mathrm{df}=18, P=0.775)$, (c) the time spent in the target quadrant in probe phase $(\mathrm{t}=0.127, \mathrm{df}=18, P=0.900)$. All data are presented as mean \pm SD. No significant difference was observed between the sham and RF groups $(P>0.05)$.

\subsection{Effect of RF Exposure on Body and Organ Weight}

As shown in Figure 6a, the body weight in both the sham and RF group increased as time was extended. However, there were no significant differences between the sham group and RF group. Furthermore, the weight gain (weight on 30th day minus weight on 0th exposure day (Figure 6b) showed that there was no difference in weight between the sham group and RF group. Similarly, the ratio of the hippocampus weight to the brain weight (Figure 6c), the ratio of the hippocampus weight to the body weight (Figure 6d), the ratio of the brain weight to the body weight (Figure 6e) did not 
change obviously in the RF group, compared with sham group. These data indicated that RF exposure had no effect on body and organ (brain, hippocampus) weight.

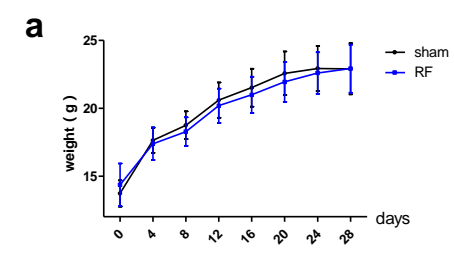

C

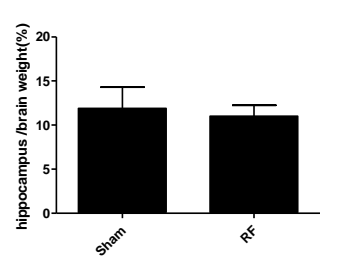

d

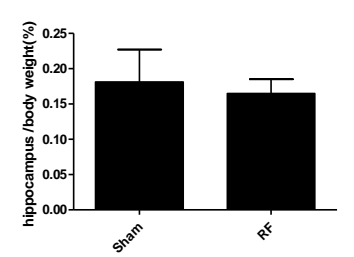

b

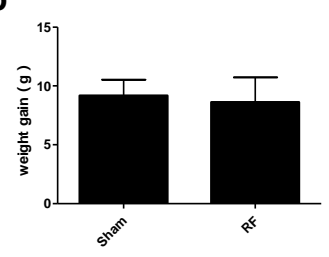

e

Figure 6. Effects of RF exposure on body and organ weight. (a) growth curve (within group: $\mathrm{df}=7$, $\mathrm{F}=657.019, P<0.001$; between groups: $\mathrm{df}=1, \mathrm{~F}=0.251, P=0.619),(\mathrm{b})$ weight gain $(\mathrm{t}=1.3, \mathrm{df}=68$, $P=0.198)$, (c) the ratio of the hippocampus weight to the brain weight $(\mathrm{t}=1.615, \mathrm{df}=48, P=0.113)$, (d) the ratio of the hippocampus weight to the body weight $(\mathrm{t}=1.751, \mathrm{df}=48, P=0.086)$, (e) the ratio of the brain weight to the body weight $(\mathrm{t}=0.145, \mathrm{df}=48, P=0.886)$. The data are presented as mean \pm SD. No significant difference was observed between the sham and RF groups $(P>0.05)$.

\subsection{Effect of RF Exposure on the Histology of the Brain}

HE staining results showed no obvious histological and morphometric differences of CA1 and CA3 and amygdala (AM) between the RF group and the sham group (Figure 7).

a

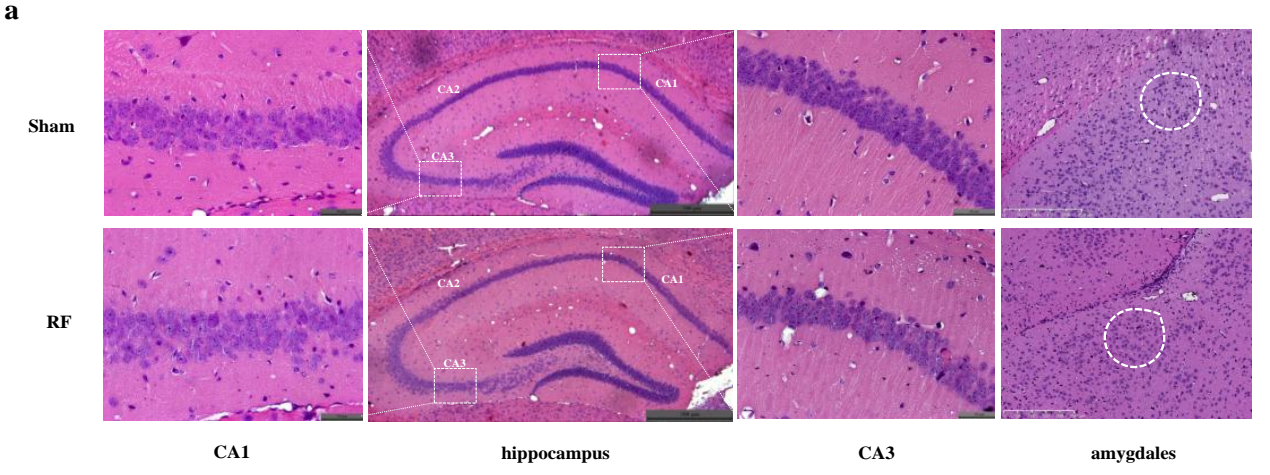

b

CA1

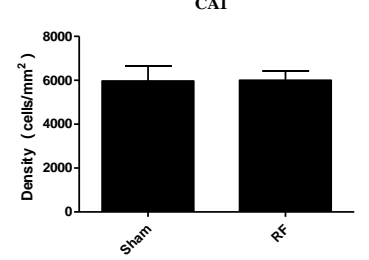

CA3

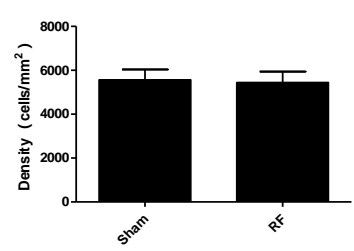

AM

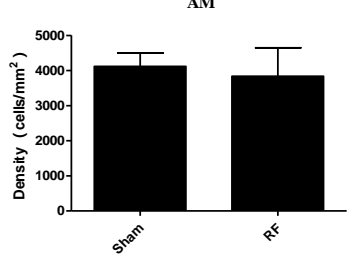

Figure 7. Effects of RF field exposure on the histology of brain. (a) The histology of hippocampus (CA1, CA3) and amygdala (AM) examined by HE staining. (b) The morphometry analysis of CA1, CA3 and AM (CA1: $\mathrm{t}=0.156, \mathrm{df}=18, P=0.878$; CA3: $\mathrm{t}=0.545, \mathrm{df}=18, P=0.593 ; \mathrm{AM}: \mathrm{t}=1.000$, $\mathrm{df}=18, P=0.333$ ). Enlargements (CA1: scale bar, $50 \mu \mathrm{m}$; hippocampus: scale bar, $500 \mu \mathrm{m}$; CA3: scale bar, $50 \mu \mathrm{m}$; amygdala: scale bar, $250 \mu \mathrm{m}$;) No significant difference was observed between the sham and RF groups $(P>0.05)$. 


\subsection{Effects of RF Exposure on the Levels of Neurotransmitters in Hippocampus and Cortex}

LC-MS results showed no obvious differences in the levels of Glu and Gly in hippocampus and cortex between the sham and RF groups. However, the levels of GABA and Asp in hippocampus and cortex were significantly decreased in the RF group, compared with the sham group (Figure 8a,b). In addition, the ratio of Glu/GABA in hippocampus and cortex did not change after RF exposure (Figure 8c,d).

a

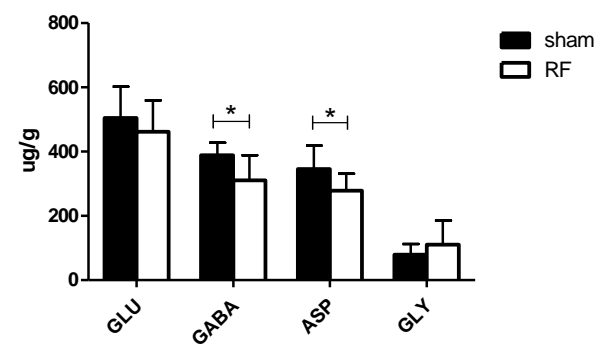

C

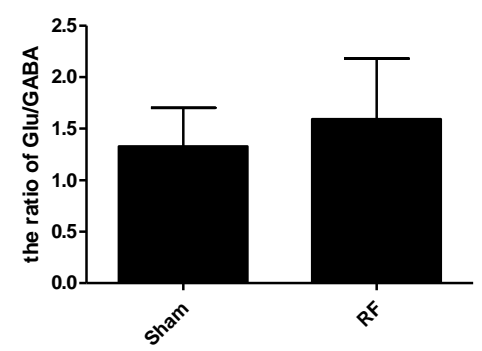

b

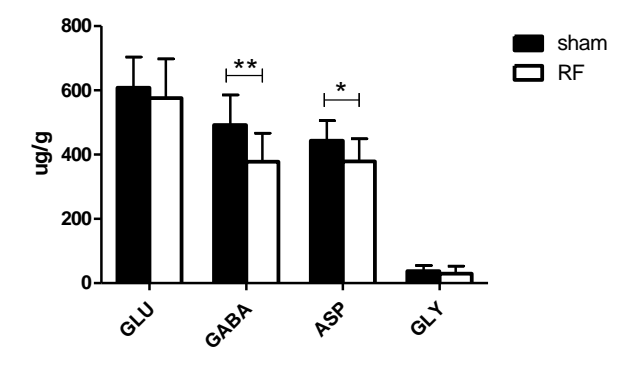

d

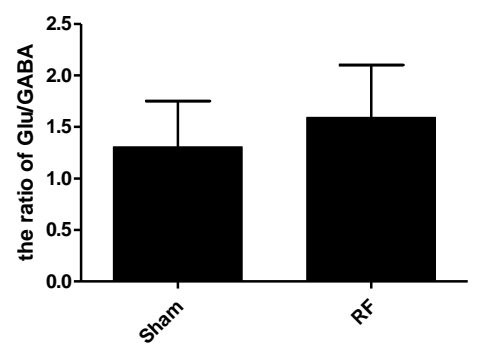

Figure 8. Effects of RF exposure on the levels of four amino acid neurotransmitters in hippocampus and cortex. (a) hippocampus (Glu: $\mathrm{t}=0.915, \mathrm{df}=16, P=0.374$; GABA: $\mathrm{t}=2.673, \mathrm{df}=16, P=0.017$; ASP: $\mathrm{t}=2.266, \mathrm{df}=16, P=0.038 ; \mathrm{Gly}: \mathrm{t}=1.132, \mathrm{df}=16, P=0.275),(\mathbf{b})$ cortex $($ Glu: $\mathrm{t}=0.659, \mathrm{df}=18$, $P=0.518$; GABA: $\mathrm{t}=2.939, \mathrm{df}=18, P=0.009 ;$ ASP: $\mathrm{t}=2.173, \mathrm{df}=18, P=0.043 ; \mathrm{Gly}: \mathrm{t}=0.889, \mathrm{df}=17$, $P=0.386)$, (c) the ratio of Glu/GABA in hippocampus $(\mathrm{t}=1.146, \mathrm{df}=16, P=0.269),(\mathrm{d})$ the ratio of Glu/GABA in cortex $(\mathrm{t}=1.342, \mathrm{df}=18, P=0.196)$. The data are presented as mean $\pm \mathrm{SD},{ }^{*} P<0.05$, ${ }^{* *} P<0.01$, compared with the sham group.

\subsection{Effects of RF Exposure on the Activity of AchE in Hippocampus and Cortex}

Acetycholine (Ach) plays an important role in learning and memory modulation. As a necessary hydrolase for Ach, AchE in hippocampus and cortex was measured after RF exposure. It was found that the activity of AchE in hippocampus and cortex did not change after RF exposure, compared with the sham group (Figure 9). 
a

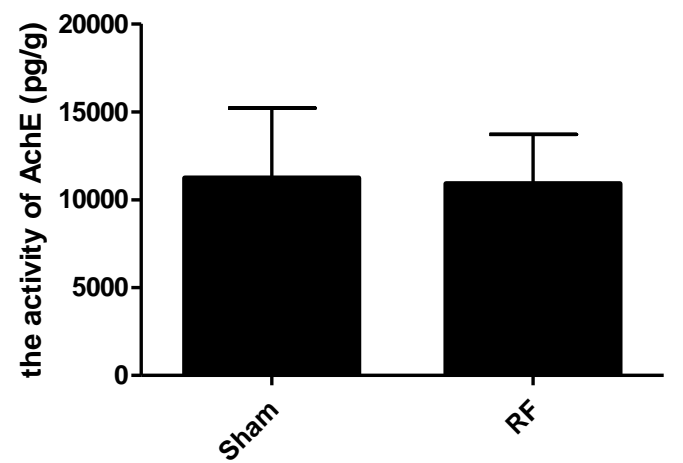

b

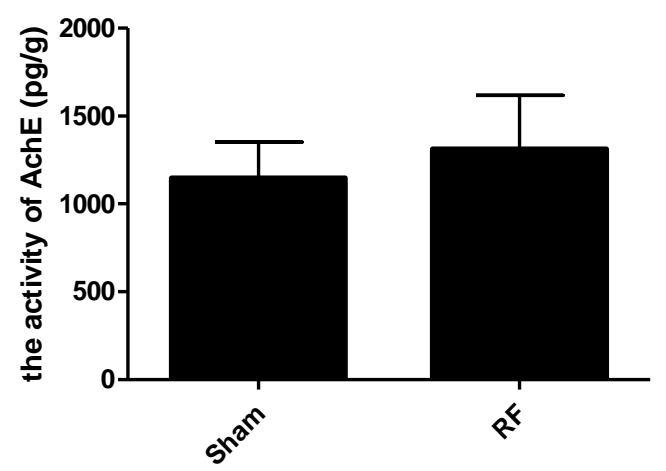

Figure 9. Effects of RF exposure on the activity of AchE in hippocampus and cortex. (a) hippocampus $(\mathrm{t}=0.172, \mathrm{df}=12, P=0.867),(\mathrm{b})$ cortex $(\mathrm{t}=1.178, \mathrm{df}=12, P=0.262)$. No significant difference was observed between the sham and RF groups $(P>0.05)$.

\section{Discussion}

In this study, a sequence of tests was performed to evaluate the effects of RF exposure on the emotional behavior and spatial memory in adolescent mice. Firstly, we evaluated the depression-like behavior by SPT, TST and FST in mice after RF exposure. It was found that the depression-like behavior in mice did not increase after RF exposure. Kumar et al. similarly reported that exposure to chronic modulated microwaves $\left(2.45 \mathrm{GHz}\right.$, power density: $0.029 \mathrm{~mW} / \mathrm{cm}^{2}$, SAR: $0.019 \mathrm{~W} / \mathrm{Kg}$ with sinusoidal modulation of $400 \mathrm{~Hz}$ ) for $2 \mathrm{~h}$ each day for 1 month had no effect on depression-like behavior in mice. However, they also reported that exposure to non-modulated microwave $(2.45 \mathrm{GHz}$, power density: $0.033 \mathrm{~mW} / \mathrm{cm}^{2}$, SAR: $0.023 \mathrm{~W} / \mathrm{Kg}$ ) for the same period caused depression-like behavior in adult male Swiss mice [20]. Kumar's findings suggested that non-modulated microwave might have much stronger effects on emotional behavior than modulated microwaves. Nevertheless, in this study, a non-modulated RF field was also used, and no effect on depression-like behavior was found. In addition, it was reported that exposure to $9.417 \mathrm{GHz}$ RF field (power intensity: $200 \mathrm{~V} / \mathrm{m}$, SAR: $2.0 \mathrm{~W} / \mathrm{kg}$ ) for $12 \mathrm{~h}$ per day during pregnancy days 3.5-18 in mice decreased depression related behavior [21]. The contradictory results could be due to the strain, the age and the gender of animals, as well as the parameters of the electromagnetic fields used in the study.

Regarding the effects of RF exposure on anxiety-like behavior, the results remain controversial. Bouji reported that exposure to RF field (900 MHz, SAR $6 \mathrm{~W} / \mathrm{kg}, 45 \mathrm{~min} /$ day for 1 month) decreased anxiety-related behaviors in both young and aged rats [11]. Kumlin found that exposure to RF field $(900 \mathrm{MHz}, \mathrm{SAR} 9 \mathrm{~W} / \mathrm{kg}$ ) for $2 \mathrm{~h} /$ day, 5 days per week (exposure from the age of 21 days to the age of 8 weeks) did not increase the level of anxiety in rats [22]. Similarly, Júnior's result showed that continuous exposure to a $1.8 \mathrm{GHz}$ Global System for Mobile (GSM) cell phone (25-s phone calls in every $2 \mathrm{~min}$, average electric field intensity when the phone was connected, $2.0 \mathrm{~V} / \mathrm{m}$, disconnected, $0.1 \mathrm{~V} / \mathrm{m}$ ) for 3 days did not change anxiety-like behavior in rats [23]. In addition, Barthelemy found that exposure to $900 \mathrm{MHz} R$ field ( $15 \mathrm{~min}$ at $0,1.5$, or $6 \mathrm{~W} / \mathrm{kg}$, or for $45 \mathrm{~min}$ at $6 \mathrm{~W} / \mathrm{kg}$ ) had no effect on anxiety-like behavior in rats [24]. However, Saikhedkar found that after exposing rats to $900 \mathrm{MHz}$ $\mathrm{RF}$ field $(0.9 \mathrm{~W} / \mathrm{kg})$ for 15 days ( $4 \mathrm{~h} /$ day), the level of anxiety increased [25], which was consistent with our results. The reason of the controversial results may due to the different experimental conditions, such as exposure devices, exposure parameters (power density, duration, exposure time), animals and so on.

The water maze is one of the most frequently used methods to evaluate the ability of spatial learning and memory, which is first reported in 1984 by Morris [26]. In this study, the MWM results showed that exposure to $1.8 \mathrm{GHz}$ RF field did not change the spatial learning and memory in mice. Similar results were reported by other research groups. For example, Sienkiewicz reported that 
exposure to $900 \mathrm{MHz}$ RF field for 45 min each day for 10 days (SAR: $0.05 \mathrm{~W} / \mathrm{kg}$ ) had no effect on spatial learning and memory abilities in mice [27]. In addition, Klose found that exposure to $900 \mathrm{MHz}$ RF field (SAR: 0.7, 2.5 and $10 \mathrm{~W} / \mathrm{kg}$ ) for $2 \mathrm{~h} /$ day, 5 days/week had no effect on spatial learning and memory abilities in juvenile, adult and presenile rats [28]. However, there are some positive results reported considering the cerebral effects of RF field. Wang found that single and high-power RF field exposure $(1.8 \mathrm{GHz}, 3.3 \mathrm{~W} / \mathrm{kg}$ ) for 30 min increased the recognition memory ability in mice [10]. Jeong reported that chronic exposure to RF-EMF (1950 MHz, SAR $5 \mathrm{~W} / \mathrm{kg}, 2 \mathrm{~h} /$ day, 5 days/week) for 8 months reduced accumulation of $A \beta$ and impairments of non-spatial and spatial memory in an Alzheimer's disease mouse model [29]. Similarly, Arendash found that exposure to long-term, high-frequency RF field ( $918 \mathrm{MHz}, 0.25 \mathrm{~W} / \mathrm{kg}, 1 \mathrm{~h} /$ day for 4-7 months) protected against and reversed cognitive impairment in Alzheimer's disease mouse model [12].

Till now, most of the procedures used in bioelectromagnetic research fields were not pharmacologically validated. With commonly accepted pharmacologically validated procedures, it is essential to (pharmacologically) validate all procedures before the exposure and make the experimental results better replicable by others.

The behavior of animals is regulated by the central nervous system. The hippocampus and amygdala are supposed to be associated with anxiety-like behavior and depression-like behavior [30,31], and the hippocampus is supposed to play an important role in learning and memory [32]. Our result showed that the histology of hippocampus and amygdala did not change in RF group, compared with sham group, which was consistent with the results of SPT, TST, FST and MWM. The result indicated that RF field had no effect on depression-like behavior and spatial learning and memory ability.

It was reported that levels of amino acid neurotransmitters such as Glu (an excitatory neurotransmitter) and GABA (an inhibitory neurotransmitter) are related to behavior [33-35], especially the emotional behavior [36]. In addition, the ratio of Glu to GABA [37] and the activity of AchE [38,39] were reported to play an important role in learning and memory ability. To confirm the behavior results and to explore the possible mechanisms, the levels of neurotransmitters and the activity of AchE were examined in mice brain. Our results showed that the value of Glu/GABA and the activity of AchE in hippocampus and cortex did not change in RF group, compared with sham group, which was consistent with the results of MWM. It was reported that GABA in mice brain, plays a key role in the modulation of anxiety response [40-43], and in this study, we found that the level of GABA in mice brain decreased significantly after RF exposure. Considering the OFT and EPM results, we speculated that the GABA probably was involved in RF induce anxiety in mice. Additionally, it was found that the level of Asp in mice brain significantly changed after RF exposure. Regarding the relationship between the behavior and Asp remains unclear.

In the present study, brain SAR $2.2 \mathrm{~W} / \mathrm{kg}$ was selected based on the $2.0 \mathrm{~W} / \mathrm{kg}$ limit by the International Commission on Nonionizing Radiation Protection (ICNIRP) and Institute of Electrical and Electronics Engineers (IEEE) [44,45]. It was found that after $6 \mathrm{~h}$ RF field exposure, the temperature of mice surface body did not change obviously compared with sham group, which suggested that no gross thermal effects were involved in RF-induced anxiety behavior in mice.

\section{Conclusions}

4-week exposure to $1.8 \mathrm{GHz} \mathrm{RF}$ field had no significant effect on depression-like behavior, spatial learning and memory ability or the histology of brain in adolescent male mice. However, it may increase the level of anxiety, and amino acid neurotransmitters such as GABA might be involved.

Acknowledgments: This work was supported by Fund of National Natural Science Foundation of China (No: 31770905) and the Special Fund from People's Liberation Army of China (PLA) of China (16CXZ020). Thank Jie Zhang in East China Normal University and Jia-Jin Lin in our department for their help in dosimetry.

Author Contributions: Gui-Rong Ding and Guo-Zhen Guo conceptualized the idea and provided their expertise for the manuscript. Jun-Ping Zhang, Ke-Ying Zhang, Ling Guo and Jing Li conceived and designed the experiments. 
Jun-Ping Zhang, Ke-Ying Zhang, Ling Guo, Qi-Liang Chen, Peng Gao and Tian Wang performed the experiments and analyzed the data. Jun-Ping Zhang, Ke-Ying Zhang and Ling Guo drafted manuscript. Jing Li, Guo-Zhen Guo and Gui-Rong Ding reviewed and revised manuscript. All of the authors above approved the final manuscript for submitting.

Conflicts of Interest: The authors declare no conflict of interest.

\section{References}

1. Petitdant, N.; Lecomte, A.; Robidel, F.; Gamez, C.; Blazy, K.; Villégier, A. Cerebral radiofrequency exposures during adolescence: Impact on astrocytes and brain functions in healthy and pathologic rat models. Bioelectromagnetics 2016, 37, 338-350. [CrossRef] [PubMed]

2. Chen, G.; Xu, Z.; Jiang, H. In vitro study on the relationship between radiofrequency electromagnetic field of mobile phone and health. Chin. J. Prev. Med. 2005, 4, 285-287.

3. Qu, B.; Wang, Y.; Xing, B.; Guo, H.; Liu, J.; Zhang, Y.; Sun, G. Effects of electromagnetic radiation on neurobehavioral and cognitive ability of mobile phones. Chin. J. Radiol. Health 2008, 1, 112-114.

4. Ministry of Environmental Protection of the People's Republic of China, General Administration of Quality Supervision, Inspection and Quarantine of the People's Republic of China. Controlling limits for electromagnetic environment. In GB8702-2014; Ministry of Environmental Protection of the People's Republic of China, General Administration of Quality Supervision, Inspection and Quarantine of the People's Republic of China: Beijing, China, 2014.

5. Scientific Committee on Emerging Newly Identified Health Risks. Opinion on potential health effects of exposure to electromagnetic fields. Bioelectromagnetics 2015, 36, 480-484.

6. International Agency for Research on Cancer. Non-Ionizing Radiation, Part 2: Radiofrequency Electromagnetic Fields. In IARC Monographs on the Evaluation of Carcinogenic Risks to Humans; WHO Press: Geneva, The Switzerland, 2013.

7. Calvente, I.; Pérez-Lobato, R.; Núñez, M.; Ramos, R.; Guxens, M.; Villalba, J.; Olea, N.; Fernández, M.F. Does exposure to environmental radiofrequency electromagnetic fields cause cognitive and behavioral effects in 10-year-old boys. Bioelectromagnetics 2016, 37, 25-36. [CrossRef] [PubMed]

8. Lamech, F. Self-reporting of symptom development from exposure to radiofrequency fields of wireless smart meters in Victoria, Australia: A case series. Altern. Ther. Health Med. 2014, 20, 28-39. [PubMed]

9. Thomee, S.; Harenstam, A.; Hagberg, M. Mobile phone use and stress, sleep disturbances, and symptoms of depression among young adults: A prospective cohort study. BMC Public Health 2011. [CrossRef] [PubMed]

10. Wang, K.; Lu, J.; Xing, Z.; Zhao, Q.; Hu, L.; Xue, L.; Zhang, J.; Mei, Y. Effect of 1.8 GHz radiofrequency electromagnetic radiation on novel object associative recognition memory in mice. Sci. Rep. 2017. [CrossRef] [PubMed]

11. Bouji, M.; Lecomte, A.; Gamez, C.; Blazy, K.; Villégier, A. Neurobiological effects of repeated radiofrequency exposures in male senescent rats. Biogerontology 2016, 17, 5-6. [CrossRef] [PubMed]

12. Arendash, G.W.; Sanchez-Ramos, J.; Mori, T.; Mamcarz, M.; Lin, X.; Runfeldt, M.; Wang, L.; Zhang, G.; Sava, V.; Tan, J.; et al. Electromagnetic field treatment protects against and reverses cognitive impairment in Alzheimer's disease mice. J. Alzheimers Dis. 2010, 19, 191-210. [CrossRef] [PubMed]

13. Aldad, T.S.; Gan, G.; Gao, X.; Taylor, H.S. Fetal radiofrequency radiation exposure from 800-1900 MHz-Rated cellular telephones affects neurodevelopment and behavior in mice. Sci. Rep. 2012. [CrossRef] [PubMed]

14. Daniels, W.M.U.; Pitout, I.L.; Afullo, T.J.O.; Mabandla, M.V. The effect of electromagnetic radiation in the mobile phone range on the behaviour of the rat. Metab. Brain Dis. 2009, 24, 629-641. [CrossRef] [PubMed]

15. Can, A.; Dao, D.T.; Terrillion, C.E.; Piantadosi, S.C.; Bhat, S.; Gould, T.D. The tail suspension test. J. Vis. Exp. 2012, 59, e3769. [CrossRef] [PubMed]

16. Can, A.; Dao, D.T.; Arad, M.; Terrillion, C.E.; Piantadosi, S.C.; Gould, T.D. The mouse forced swim test. J. Vis. Exp. 2012, 59, e3638. [CrossRef] [PubMed]

17. Vorhees, C.V.; Williams, M.T. Morris water maze: Procedures for assessing spatial and related forms of learning and memory. Nat. Protoc. 2006, 1, 848-858. [CrossRef] [PubMed]

18. Ju, G.; Zhao, X. Practical Experimental Techniques in Neurobiology; The Fourth Military Medical University press: Xi'an, China, 2012; pp. 52-60. 
19. Sari, Y.; Hammad, L.A.; Saleh, M.M.; Rebec, G.V.; Mechref, Y. Alteration of selective neurotransmitters in fetal brains of prenatally alcohol-treated C57BL/6 mice: Quantitative analysis using liquid chromatography/tandem mass spectrometry. Int. J. Dev. Neurosci. 2010, 28, 263-269. [CrossRef] [PubMed]

20. Kumar, M.; Singh, S.P.; Chaturvedi, C.M. Chronic nonmodulated microwave radiations in mice produce anxiety-like and depression-like behaviours and calcium- and no-related biochemical changes in the brain. Exp. Neurobiol. 2016, 25, 318. [CrossRef] [PubMed]

21. Zhang, Y.; Li, Z.; Gao, Y.; Zhang, C. Effects of fetal microwave radiation exposure on offspring behavior in mice. J. Radiat. Res. 2015, 56, 261-268. [CrossRef] [PubMed]

22. Kumlin, T.; Iivonen, H.; Miettinen, P.; Juvonen, A.; van Groen, T.; Puranen, L.; Pitkaaho, R.; Juutilainen, J.; Tanila, H. Mobile phone radiation and the developing brain: Behavioral and morphological effects in juvenile rats. Radiat Res. 2007, 168, 471-479. [CrossRef] [PubMed]

23. Júnior, L.C.D.C.; Guimarães, E.D.S.G.; Musso, C.M.; Stabler, C.T.; Garcia, R.M.G.; Mourão-Júnior, C.A.; Andreazzi, A.E. Behavior and memory evaluation of Wistar rats exposed to $1.8 \mathrm{GHz}$ radiofrequency electromagnetic radiation. Neurol. Res. 2014, 36, 800-803. [CrossRef] [PubMed]

24. Barthélémy, A.; Mouchard, A.; Bouji, M.; Blazy, K.; Puigsegur, R.; Villégier, A. Glial markers and emotional memory in rats following acute cerebral radiofrequency exposures. Environ. Sci. Pollut. Res. 2016, 23, 25343-25355. [CrossRef] [PubMed]

25. Saikhedkar, N.; Bhatnagar, M.; Jain, A.; Sukhwal, P.; Sharma, C.; Jaiswal, N. Effects of mobile phone radiation (900 MHz radiofrequency) on structure and functions of rat brain. Neurol. Res. 2014, 36, 1072-1079. [CrossRef] [PubMed]

26. Morris, R. Developments of a water-maze procedure for studying spatial learning in the rat. J. Neurosci. Methods 1984, 11, 47-60. [CrossRef]

27. Sienkiewicz, Z.J.; Blackwell, R.P.; Haylock, R.G.; Saunders, R.D.; Cobb, B.L. Low-level exposure to pulsed $900 \mathrm{MHz}$ microwave radiation does not cause deficits in the performance of a spatial learning task in mice. Bioelectromagnetics 2000, 21, 151-158. [CrossRef]

28. Klose, M.; Grote, K.; Spathmann, O.; Streckert, J.; Clemens, M.; Hansen, V.W.; Lerchl, A. Effects of early-onset radiofrequency electromagnetic field exposure (GSM $900 \mathrm{MHz}$ ) on behavior and memory in rats. J. Vis. Exp. 2014, 182, 435-447. [CrossRef] [PubMed]

29. Jeong, Y.J.; Kang, G.Y.; Kwon, J.H.; Choi, H.D.; Pack, J.K.; Kim, N.; Lee, Y.S.; Lee, H.J. 1950 MHz electromagnetic fields ameliorate $\mathrm{A} \beta$ pathology in Alzheimer's disease mice. Curr. Alzheimer. Res. 2015, 12, 481-492. [CrossRef] [PubMed]

30. Belzung, C.; Turiault, M.; Griebel, G. Optogenetics to study the circuits of fear- and depression-like behaviors: A critical analysis. Pharmacol. Biochem. Behav. 2014, 122, 144-157. [CrossRef] [PubMed]

31. Meyer-Lindenberg, A. Behavioural neuroscience: Genes and the anxious brain. Nature 2010, 466, 827-828. [CrossRef] [PubMed]

32. Bird, C.M.; Burgess, N. The hippocampus and memory: Insights from spatial processing. Nat. Rev. Neurosci. 2008, 9, 182-194. [CrossRef] [PubMed]

33. Heresco-Levy, U. Glutamatergic neurotransmission modulation and the mechanisms of antipsychotic atypicality. Prog. Neuro-Psychopharmacol. Biol. Psychiatry 2003, 27, 1113-1123. [CrossRef] [PubMed]

34. HYND, M. Glutamate-mediated excitotoxicity and neurodegeneration in Alzheimer's disease. Neurochem. Int. 2004, 45, 583-595. [CrossRef] [PubMed]

35. Millan, M.J. The neurobiology and control of anxious states. Prog. Neurobiol. 2003, 70, 83-244. [CrossRef]

36. Cavalcante, G.I.; Chaves, F.A.; Linhares, M.I.; de Carvalho, L.C.; Venancio, E.T.; Rios, E.R.; de Souza, F.C.; Vasconcelos, S.M.; Macedo, D.; de Franca, F.M. HIV antiretroviral drug Efavirenz induces anxiety-like and depression-like behavior in rats: evaluation of neurotransmitter alterations in the striatum. Eur. J. Pharmacol. 2017, 799, 7-15. [CrossRef] [PubMed]

37. Li, Y.; Wang, D.; Peng, R.; Li, Z.; Dong, B.; Dong, F.; Liang, Y.; Hu, W. Effects of electromagnetic pulse on contents of amino acids in hippocampus of rats. Chin. J. Ind. Hyg. Occup. Dis. 2003, 5, 6-8.

38. Blokland, A. Acetylcholine: A neurotransmitter for learning and memory. Brain Res. Rev. 1995, 21, $285-300$. [CrossRef]

39. Winkler, J.; Suhr, S.T.; Gage, F.H.; Thal, L.J.; Fisher, L.J. Essential role of neocortical acetylcholine in spatial memory. Nature 1995, 375, 484-487. [CrossRef] [PubMed]

40. Lydiard, R.B. The role of GABA in anxiety disorders. J. Clin. Psychiatry 2003, 64, 21-27. [PubMed] 
41. Nemeroff, C.B. The role of GABA in the pathophysiology and treatment of anxiety disorders. Psychopharmacol. Bull. 2003, 37, 133-146. [PubMed]

42. Olexová, L.; Štefánik, P.; Kršková, L. Increased anxiety-like behaviour and altered GABAergic system in the amygdala and cerebellum of VPA rats-An animal model of autism. Neurosci. Lett. 2016, 629, 9-14. [CrossRef] [PubMed]

43. Zhang, W.; Zhao, R.; Li, X.; Cui, X.; Zhao, Z.; Mao, Y.; Wu, F.; Tang, Q. Effect of Yi-nao-jie-yu decoction on $\gamma$-aminobutyric acid type A receptor in the hippocampus and serum inflammatory factors in a rat model of post stroke anxiety. Neuropsychiatric Dis. Treat. 2016, 12, 2827-2837. [CrossRef] [PubMed]

44. International Commission on Non-Ionizing Radiation Protection. Guidelines for limiting exposure to time-varying electric magnetic and electromagnetic fields (up to $300 \mathrm{GHz}$ ). Health Phys. 1998, 74, 494-522.

45. Institute of Electrical and Electronics Engineers. IEEE Standard for Safety Levels with Respect to Human Exposure to Radio Frequency Electromagnetic Fields, $3 \mathrm{kHz}$ to $300 \mathrm{GHz}$, IEEE Std C95.1 ${ }^{\mathrm{TM}}$-2005; IEEE: New York, NY, USA, 2006.

(c) 2017 by the authors. Licensee MDPI, Basel, Switzerland. This article is an open access article distributed under the terms and conditions of the Creative Commons Attribution (CC BY) license (http://creativecommons.org/licenses/by/4.0/). 